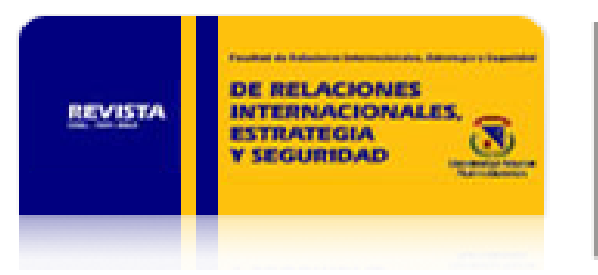

Revista de Relaciones Internacionales, Estrategia y Seguridad

ISSN: 1909-3063

cinuv.relinternal@unimilitar.edu.co

Universidad Militar Nueva Granada

Colombia

Losada Sierra, Manuel

ORIGEN Y DESARROLLO DEL IUSNATURALISMO EN TOMAS DE AQUINO

Revista de Relaciones Internacionales, Estrategia y Seguridad, vol. 4, núm. 2, julio-diciembre, 2009,

pp. 109-125

Universidad Militar Nueva Granada

Bogotá, Colombia

Disponible en: http://www.redalyc.org/articulo.oa?id=92712972002

Cómo citar el artículo

- Número completo

- Más información del artículo

- Página de la revista en redalyc.org

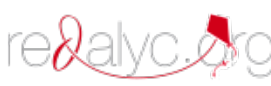

Sistema de Información Científica

Red de Revistas Científicas de América Latina, el Caribe, España y Portugal

Proyecto académico sin fines de lucro, desarrollado bajo la iniciativa de acceso abierto 
rev.relac.int.estrateg.segur.4(2):109-125,2009

\title{
ORIGEN Y DESARROLLO DEL IUSNATURALISMO EN TOMAS DE AQUINO*
}

\author{
Manuel Losada Sierra**
}

\section{RESUMEN}

El presente artículo busca establecer el origen y desarrollo del concepto de ley natural en Tomás de Aquino, especialmente la relación que se establece entre razón y voluntad. Recordemos que esta relación ha sido objeto de numerosos estudios, especialmente en referencia al mismo concepto en Francisco Suárez. El artículo trata el tema de manera objetiva y como testigo de lo que nuestro teólogo pensó y estableció en sus escritos. Al calificarlo como teólogo, entendemos desde dónde está hablando, es decir, desde su condición de creyente y teniendo como fuente la misma Revelación.

Palabras Clave: Ley, naturaleza, iusnaturalismo, acto humano, razón, voluntad.

\footnotetext{
* El presente artículo forma parte del trabajo de investigación que el autor desarrolló en la Pontificia Universidad Gregoriana (Roma), para alcanzar el título de Magister en Filosofía Política. El trabajo de maestría busca establecer una comparación entre las posiciones de Tomás de Aquino y Francisco Suárez en la concepción de la ley natural.

** Director Departamento de Humanidades, Universidad Militar Nueva Granada. Correo electrónico: manuel.losada@unimilitar.edu.co
} 


\begin{abstract}
This article seeks to establish the origin and development of the concept of natural law in St. Thomas Aquinas, especially the relation that is established between reason and will. Let us remember that this relation has been the object of numerous studies, especially with reference to the same concept in Francisco Suarez' work. The article deals with the subject in an objective way and as witness of what our theologian thought and established in his writings. When we qualify him as theologian, we understand where he is talking from, that is to say, from his condition of believer having as source revelation itself.
\end{abstract}

Key Words: Law, nature, iusnaturalism, human act, reason, will.

\title{
1. INTRODUCCIÓN
}

Si bien, hoy en día el concepto de ley natural no goza de una gran acogida entre los filósofos y pensadores, especialmente porque no se considera que sobre el concepto de naturaleza se pueda fundar alguna norma de comportamiento. Tan bien es cierto que el pensamiento iusnaturalista tuvo una gran influencia en el desarrollo de la perspectiva ética y de algunos conceptos que hoy en día son acogidos como patrimonio del pensamiento humano. Pensemos en algunas ideas que tuvieron en el iusnaturalismo el espacio de nacimiento y crecimiento, p. ej., bien común, derechos de gentes, derechos humanos, derecho internacional humanitario, para citar algunos. De otra parte, la ley natural continúa siendo la base de la moral que orienta el pensamiento de la Iglesia Católica, seguida por millones de personas en el mundo. Estas constataciones nos permiten suponer que continúa siendo de gran interés el estudio del pensamiento iusnaturalista desde la perspectiva de la filosofía política. En este contexto, el pensamiento de Tomás de Aquino ha tenido una gran influencia. Queremos en este artículo recoger el nacimiento y desarrollo del iusnaturalismo en nuestro autor, para lo cual hemos acudido a los textos más importantes en los que pudiéramos rastrear las huellas de su pensamiento.

Haremos, entonces, en el primer punto una aproximación global al concepto de Ley en general, centrando nuestra atención fundamentalmente en la relación razón-voluntad. Luego, al hablar específicamente de la Ley Natural, ampliaremos estos conceptos teniendo como fondo de nuestro trabajo la fundamentación metafísica y antropológica.

\section{CONCEPTO DE LEY}

Iniciamos nuestro trabajo adentrándonos en la reflexión de Tomás de Aquino. Para ello tomamos como base el Tratado «De Legibus», inserto en la «Suma Teológica» (SANTO TOMAS DE AQUINO, 
1947) ${ }^{1}$ por ser ésta la obra de su madurez y en donde encontramos de modo sistemático muchos elementos que eran solamente insinuados en las obras precedentes o, si bien eran claramente definidos, se encontraban dispersos. Para ubicar en su contexto preciso la reflexión, nos remitiremos a otros lugares de la Suma Teológica indispensables para entender la fundamentación tomista. De igual manera tenemos en cuenta lugares paralelos de otras obras, especialmente el "Comentario a las Sentencias», el "Comentario a la Ética Nicomaquea» y la "Suma contra los Gentiles».

Santo Tomas al iniciar el tratado «De Legibus» en la introducción a la q. 90, ubica la reflexión de la ley dentro del contexto de los actos humanos, y más precisamente dice que hablará de los «principios exteriores de nuestros actos»; es decir, de las realidades que influyen de alguna manera en dichos actos. Uno de ellos es precisamente la ley, que por ser ordenación del actuar humano se pone en contacto directo con la razón y la voluntad, las dos potencias de la acción humana (SANTO TOMAS DE AQUINO, 1947: I-II, q. 1, a.1). En efecto, la definición de Santo Tomás en la Suma Teológica parte de esta consideración: la ley es una ordinatio rationis. El motivo de esta afirmación se fundamenta en el hecho de que la ley es una norma directiva del actuar humano en vistas al fin último (SANTO TOMAS DE AQUINO: 1947: q. 90, a. 2). Para entender el alcance de este concepto debemos aclarar el contexto en el que se mueve la reflexión.

Para Santo Tomás el factor que preside y determina el orden de la acción es el fin (S. THOME AQUINATIS, 1931: VII, lect. 8, n. 1431), es decir, identifica el obrar humano con el obrar por un fin ; esto no quiere decir que sea exclusivo del hombre la tendencia al fin, porque todos los agentes obran por un fin y todas las cosas están inclinadas a desear el bien según el modo propio de ser (SANTO TOMAS DE AQUINO, 1952: III, c. 2), sino más bien que no puede existir un acto humano en donde la voluntad y la razón, como facultades del libre albedrío, no tengan un objeto por el cual actuar o hacia el cual tender (SANTO TOMAS DE AQUINO, 1947: I-II, q. 1, a. 2). Ahora bien, la aprehensión del fin y la deliberación sobre los medios para alcanzarlo es propio de la razón, esto aparece claro si consideramos que la razón constituye al hombre en su especie, o dicho de otra manera es la forma, o acto primo que lo especifica como ser humano y lo distingue de los demás animales, constituyéndose de esta manera en fuente de actividad De este modo, la razón establece un plano de acción en donde los medios sean adecuados y proporcionados al fin; por ésto es precisamente la regla universal del actuar humano. Este es el orden de la razón práctica que conoce la regla de acción y la aplica, mientras la especulativa trata de principios universales.

Santo Tomas toma así en el tratado «De Legibus» algunos principios de la metafísica de Aristóteles, según los cuales el fin es la causa primordial en el orden práctico y la razón, como facultad cognoscitiva del fin, es en el hombre la regla o norma de su actuar. La razón es la regla general del actuar humano, mientras la ley es una regla determinada; pertenece, por tanto, la ley a la razón (SANTO TOMAS DE AQUINO, 1947: I-II, q. 90, a. 1, sed contra).

\footnotetext{
${ }^{1}$ Específicamente, este Tratado se encuentra en Summa Theol., I-II, qq. 90-97.
} 
Podemos preguntarnos ¿qué función cumple la voluntad dentro de este esquema? Comentando el primer libro de la Ética de Aristóteles dice Santo Tomas que la filosofía moral tiene por objeto el acto humano ordenado a un fin, y este acto humano realiza el orden de la razón según la orientación de la voluntad. Una acción es humana, en efecto, cuando es ejecutada por la voluntad dentro de un esquema intencional establecido y organizado por la razón.

La pieza clave de dicho esquema es necesariamente el fin, ya que lo que define y constituye la entidad de la acción, como habíamos dicho precedentemente, es su tensión de algo o hacia algo. Así, la operación de la voluntad ordenada por la razón a un fin son los tres elementos fundamentales que integran el orden operacional humano. Nos aclara mucho más las respuesta de Santo Tomás a la tercera objeción al a. 1 de la q. 90 en la I-II: se quiere sostener que la ley pertenece a la voluntad y no a la razón porque característica de la ley es mover a obrar, y esto lo realiza propiamente la voluntad según lo que había demostrado anteriormente en el a. 1 de la q. 9. Santo Tomás responde:

«El poder de mover que tiene la razón lo recibe de la voluntad, según dijimos, pues cuando alguien quiere el fin es cuando la razón dispone acerca de los medios que a él conducen. Pero para que el querer de la voluntad respecto de estos medios tengan valor de ley es necesario que esté regulada por la razón» (SANTO TOMAS DE AQUINO, 1947: I-II, q. 17, a. 1)

Es decir, acepta que la ley mueva y que esa moción pertenezca de un modo especial a la voluntad, pero ésta viene regulada por la razón. Podemos decir, que el acto de la razón práctica es formalmente un acto de la razón porque consiste en establecer un orden, organizar y dirigir un plan de ejecución; pero supone necesariamente un acto de la voluntad porque quiere el fin, elige medios y mueve a actuar. De este modo la voluntad participa de la racionalidad propia del hombre, por esto es una voluntad racional.

\section{EL CONCEPTO DE LEY NATURAL.}

Hablando de la ley en general habíamos dicho cómo en toda operación humana intervienen dos principios, el apetitivo (voluntad) y el cognoscitivo (razón). La ley es una ordenación de la operación humana, por tanto, está en contacto con esos dos principios. La ordenación supone la inclinación o proclividad del apetito hacia el fin, es decir, supone el principio que ejecuta el movimiento que es ordenado y dirigido; igualmente, supone el conocimiento de ese fin, de otra manera no podría ordenar algo hacia él. Al entrar en el específico estudio de la Ley Natural, nos preguntamos ¿cómo pueden estar las cosas, y el hombre en particular, ordenados hacia el fin?, y ¿cómo se da la relación razón-voluntad en la noción de Ley Natural?

\subsection{LA LEY NATURAL Y LA LEY ETERNA}

Ya en el primer libro de su "Comentario a las Sentencias», Santo Tomás afirma cómo todas las cosas están sujetas a la Providencia divina y son dirigidas por ella; cada una según su modo de ser propio.

ORIGEN Y DESARROLLO DELIUSNATURALISMO ENTOMAS DE AQUINO 
El hombre no es una excepción en este conjunto de orden y de armonía. De igual manera que las cosas naturales tienden hacia el fin que les ha sido prefijado, impulsados por las fuerzas activas que la Divina Providencia les ha infundido para ello, así la voluntad humana se ve movida y guiada hacia su propio fin, por medio de los consejos y preceptos que el mismo Dios le da. Para Santo Tomás la noción de Ley Eterna está inmediatamente unido a la de Providencia, aquella es el plano (ratio) abstracto del orden universal de las cosas al fin, la Providencia es el plano concreto del orden particular de cada cosa singular al fin (SAN TOMMASO D'AQUINO, 1992: q. 5, a. 1, ad 6).

En la Suma Teológica encontramos la Ley Natural dentro del amplio marco del gobierno que Dios ejerce en el universo. Ya en la primera parte se afirma que la voluntad divina es causa de todos los seres, que la ciencia divina es el origen y fundamento de todas las cosas. En esta perspectiva, toda inclinación o movimiento de las criaturas, todo lo que en ellas contribuye al buen orden de sus actos hacia el fin que les corresponde, se considera como manifestaciones concretas de la Divina Providencia e impulsos particulares del gobierno que Dios ejerce sobre los seres.

A la Divina Providencia, dice, corresponde ordenar las cosas respecto de su propio fin. En este contexto hasta la mínima razón de orden ha de provenir de Dios, autor de todo bien y fuente primera de todo orden. Dios es el creador de las cosas y por esto las ordena y dirige en vistas a conseguir sus fines correspondientes.

La Ley Natural es definida por Santo Tomás como «participación de la Ley Eterna en la criatura racional» (SANTO TOMAS DE AQUINO, 1947: I-II, q. 91, a. 2). La Ley Eterna, como toda ley es dictamen de la razón práctica del que gobierna una comunidad; en este caso Dios, como el gobernante, y el Universo, como la comunidad. Es algo así como el plan de gobierno que Dios se ha fijado desde la eternidad para regir la marcha del mundo en vistas del fin último; y precisamente desde esta perspectiva Santo Tomás explica la promulgación de la Ley Natural, ésta se da en el momento mismo en que Dios la imprime, como legislador, en la mente humana. Esta explicación es fundamental dentro del concepto de ley, porque ésta para tener fuerza obligatoria debe ser puesta ante la comunidad y dada a conocer a aquellos a quienes está dirigida.

Podemos ahora analizar la forma concreta como el hombre participa de la Ley Eterna, de esta como dice Santo Tomás, «Razón o plano de la divina sabiduría, relativo a toda acción y a todo movimiento» (SANTO TOMAS DE AQUINO, 1947: I-II, q. 90, a. 4).

\subsection{LA LEY NATURAL Y LAS INCLINACIONES NATURALES.}

Iniciamos este apartado, aclarando el concepto de naturaleza que maneja Santo Tomás cuando habla de Ley Natural. Esta aclaración la creo necesaria para poder comprender, dentro del orden sistemático de nuestro autor, la relación existente entre Ley Natural, inclinaciones y preceptos. Temas que abordaremos en los siguientes apartados. 


\subsubsection{Concepto de naturaleza y natural.}

En el Comentario a la Metafísica Santo Tomás analiza al menos cinco nociones del término naturaleza, estudiados por Aristóteles. Al final del análisis, a modo de conclusión, afirma que en un sentido propio naturaleza es la forma de aquellas cosas que tienen en sí mismas el principio de operación (S. THOME AQUINATIS, 1950: V, lect. 5, n.826).

Y en el "De ente et essentia» propone la clásica definición: «El término naturaleza fue asumido para significar la esencia de la cosa en cuanto está ordenada a la operación propia de la cosa misma, porque a ninguna cosa puede faltar una operación propia» (S. THOME AQUINATIS, 1954: c.1).

Y precisa que el término naturaleza designa la esencia en relación a la generación y a la acción, mientras la esencia como tal expresa una cosa en cuanto por ella y en ella tiene el ser. De este modo, en cuanto principio intrínseco de las cosas, natural será lo que es causado o puede ser causado por los principios naturales intrínsecos (S. THOME AQUINATIS, 1929: In IV Sent., d. 17, q. 3, a. 1, sol. 2); y en cuanto intentio, o tensión hacia un fin, expresará aquello hacia lo cual la naturaleza está inclinada (S. THOME AQUINATIS, 1929: In III Sent., d. 20, q. 1, a. 1, sol, 1, ad 1). Por esto, el bien está en conformidad con la inclinación natural. Precisamente, porque el fin de todo ser puede remitirse a su propia perfección, natural será, en un determinado sujeto, aquello que sirve a su perfeccionamiento, e igualmente la Ley Natural expresará la forma en cuanto inclinada al propio fin. En el hombre, la razón es por excelencia la forma que lo distingue de los otros animales, por esto, la naturaleza expresará el alma racional en su inclinación al fin último.

Santo Tomás dice que todas las criaturas participan de la Ley Eterna en cuanto que reciben una «inclinación a los propios actos y a los propios fines», pero el hombre participa de una forma especial porque «participa de la providencia como tal, y es providente para sí mismo y para los demás» (SANTO TOMAS DE AQUINO, 1947: I-II, q. 91, a. 2), es decir, ha sido provisto de una inclinación natural que lo induce a su debido fin y a realizar sus actos de modo adecuado para conseguirlo. Así, encontramos en el hombre un doble aspecto de la participación de la Ley eterna (que es la Ley Natural): como una inclinación natural y como un acto responsable de la razón que la asume.

Ya en el Comentario a las Sentencias encontramos, sin referencia directa a la Ley Eterna, estos dos aspectos de la Ley Natural, que aquí Santo Tomás Ilama naturalis conceptio y naturalis inclinatio, dice que éstos son los principios necesarios del actuar humano que hacen la acción apropiada al fin, y por tanto orientan a obrar rectamente (S. THOME AQUINATIS, 1929: In IV Sent., d. 33, q. 1, a. 2). En el hombre se da una íntima relación entre estos aspectos: "Y como la forma propia del hombre es el alma racional, todo el hombre se siente naturalmente inclinado a obrar de acuerdo con la razón» (SANTO TOMAS DE AQUINO, 1947: I-II, q. 94, a. 3).

Así, la razón debe iluminar y dirigir la realidad humana que posee ya en sí misma inclinaciones y orientaciones precisas que son expresión de su naturaleza. Veamos más de cerca cómo se da esta participación de la Ley Eterna en la voluntad y en la razón.

ORIGEN Y DESARROLL DELIUSNATURALISMO ENTOMAS DE AQUINO 


\subsubsection{La inclinación de la voluntad.}

La participación de la Ley Eterna se da en la voluntad como la impresión o inserción de una inclinación al fin y a la operatividad que orienta convenientemente el hombre al bien. La Ley Natural, dice Santo Tomás, es esta inclinación connatural hacia el acto y el fin debidos. Es una orientación que nos impulsa al bien y nos aleja del mal. Así pues, la Ley Natural es la inclinación natural o la orientación de la naturaleza humana al bien que la razón debe escuchar y seguir, es por tanto una ley inscrita en el fondo del ser, anterior a todo conocimiento intelectual, que inclina el ser al fin y a la operación respectiva.

\subsubsection{El juicio de la razón}

Aquí la Ley Natural se presenta como la impresión o inserción de una luz que nos permite discernir los principios del bien y del mal. Esta afirmación nos remite inmediatamente a la doctrina de Santo Tomás sobre la sindéresis. En el Comentario a las Sentencias, afirma que tanto en el orden especulativo como en el orden práctico existe una virtus intellectiva mediante la cual se captan directamente algunas verdades, sin necesidad de indagar. En el orden práctico, que es el orden del obrar, este habitus se llama sindéresis y permite, por un lado la elaboración de los primeros principios, por sí mismos evidentes, y por otro los contiene (S. THOME AQUINATIS, 1929: In II Sent., d. 39, q. 3, a. 4).

Sobre este aspecto es iluminante la respuesta de Santo Tomás a una objeción al a. 4 de la q. 90 en la I-II: se quiere sostener que la promulgación no es esencial a la ley en cuanto que la Ley Natural, que es «maxime habet rationem legis», no necesita promulgación. Santo Tomás responde: «la promulgación de la ley natural se ha realizado por el hecho de que Dios la ha impreso en las mentes de los hombres, y por esta impresión es naturalmente cognoscible» ${ }^{2}$

Queremos aquí recalcar que la Ley Natural ha sido inserida por Dios para ser conocida naturalmente, y de este modo el hombre en las circunstancias particulares en que se encuentre pueda realizar el bien. De aquí que la razón práctica pueda a partir de esta luz discernir los principios del bien y del mal y deducir luego los medios operativos concretos para alcanzar el fin.

La razón humana conoce lo que es bien y lo que es mal analizando la orientación puesta por Dios en la naturaleza; de este modo, reconoce como bien, y por tanto algo que debe ser alcanzado mediante la actividad, todo aquello hacia lo cual siente una inclinación natural; lo opuesto es reconocido como mal, y debe ser evitado. Así, es siempre la razón la que juzga la bondad de las inclinaciones y de las normas que son buenas, en cuanto la razón las aprehende como buenas; y, por esto la ley, como decíamos, es siempre aliquid rationis. De esta forma, se da una integración dinámica entre la naturalis inclinatio y la naturalis conceptio, es decir, entre la verdad sobre el bien de la razón y la tendencia al bien de la voluntad. Podemos afirmar siguiendo esta línea de reflexión que en el hombre se dan dos fuentes naturales de orden al bien: la una tiene por sede la razón

\footnotetext{
${ }^{2}$ A este texto nos habíamos referido antes para mostrar la promulgación como obra de Dios gobernante. Cf. supra p. 7, nota 24 .
} 
práctica y está constituida, como veremos a continuación, por un núcleo de principios evidentes; la otra radica en el apetito natural y consiste en un cierto número de inclinaciones espontáneas, que descubriremos igualmente en el siguiente numeral.

\subsubsection{Los preceptos de ley natural}

Hemos precedentemente aclarado cómo en la naturaleza humana existen unas inclinaciones naturales hacia el bien, que funcionan como direcciones o valores hacia los cuales la razón dirige su actividad. Pues bien, para Santo Tomás los preceptos de la Ley Natural siguen el orden de las inclinaciones naturales (; de modo que no se da Ley Natural que no presuponga como fundamento nexos objetivos correspondientes, la deontología presupone una ontología (Cf. VENDEMIATI, 1995: 122). Pero veamos desde el principio su argumentación en la Suma Teológica, haciendo cuando sea necesario, referencias a las otras obras utilizadas.

Apoyándose en la simetría estructural que existe entre la razón especulativa y la razón práctica comienza diciendo que, así como la idea de ser es la primera que aparece dentro de todo conocimiento humano, por eso el primer principio indemostrable -no se puede afirmar y negar una cosa al mismo tiempo, es el que se funda directamente sobre ella; de igual manera, la idea de bien es la primera que cae dentro del conocimiento propio de la razón práctica, pues ésta se ordena siempre a la acción y es sabido que nadie obra sino en busca de un bien o fin, así que el primer precepto de la Ley Natural no será otro que el fundado de inmediato en la misma idea de bien, es decir, el de hay que hacer el bien y evitar el mal. Este es el primer precepto, universalísimo, sobre el cual se fundan todos los demás preceptos y prohibiciones naturales. Santo Tomás no había hablado en sus obras anteriores de un primer precepto único de la Ley Natural, aunque si reconoce la existencia de unos preceptos primeros y otros segundos, por ejemplo en el Comentario a las Sentencias y en el Comentario a la Ética de Aristóteles ${ }^{3}$.

Es éste el primer precepto porque proviene de los conceptos de bien y de mal, que son los primeros conceptos en el orden práctico; el bien es el fin al que tiende la actividad práctica y el mal se opone al bien. Por esto mismo es el concepto más claro, evidente por sí mismo. Es, sin embargo, un precepto abstracto e indeterminado por ser un denominador común de todo precepto justo, es una especie de estructura formal que revestida de materia concreta, da origen a cada uno de los preceptos, tanto naturales como positivos; de ahí que este primer principio necesite un contenido, una materia (Cf. VAN OVERBEKE, 1957: 455). Pero, ¿cómo establecer los restantes preceptos de la Ley Natural? Dice Santo Tomás que en el hombre el precepto de "hay que hacer el bien y evitar el mal», equivale al de «hay que hacer aquello que la razón práctica considera naturalmente como bien y evitar lo que ella juzgue inconveniente o malo" (SANTO TOMAS DE AQUINO, 1947: I-II, q. 94, a. 2). Prosigue diciendo que como el bien tiene razón de fin y el mal tiene razón de todo lo contrario,

\footnotetext{
${ }^{3}$ Se puede confronter: In IV Sent., d. 33, q.1, a.1; In Ethic. V, lect.12, n. 1023.

ORIGEN Y DESARROLLO DEL IUSNATURALISMO ENTOMAS DE AQUINO
} 
la razón práctica toma naturalmente como bien y algo a poner en práctica, todo aquello que constituye los fines naturales del hombre, aquello a lo que éste último siente inclinación natural; y considera naturalmente como mal y algo a evitar, todo cuanto impide u obstaculiza la consecución de dichos fines, oponiéndose a las inclinaciones naturales (SANTO TOMAS DE AQUINO, 1947: Ibid).

Llegados a este punto no es necesario sino descubrir cuáles son los verdaderos fines a que nos sentimos inclinados por naturaleza, para poder señalar cuáles son los principales preceptos (porque no intenta dar un elenco completo), directamente prácticos de la Ley Natural. Tras asentar, como vimos anteriormente, que el orden de los preceptos de la Ley Natural es correlativo al de las inclinaciones o tendencias naturales, pasa a reunir todas éstas alrededor de las tres que, a su entender, son las fundamentales. En efecto, examinando la naturaleza humana podemos encontrar inclinaciones naturales y fundamentales puestas por Dios. Estas inclinaciones son:

A. Inclinación a permanecer siempre en la existencia, inclinación que brota del fondo de la naturaleza común a todo ser. Es la inclinación ontológica a la propia conservación, a perseverar en la existencia. Así, pertenece a la Ley Natural lo relativo a la conservación del ser individual. Aquí se incluye lo que tiene de común el hombre con todas las cosas creadas.

B. Inclinación hacia el bien que le corresponde por tener una naturaleza común con todos los animales irracionales; y en este sentido, de ley natural es aquello que la naturaleza enseña por igual a todos los animales. Es la inclinación al bien de la especie, y pertenece a la Ley Natural, p.ej., la unión hombre-mujer, la educación de los hijos, etc.

C. Inclinación hacia el bien particular de su naturaleza racional. Estamos en el campo específico del hombre racional-social. Esta inclinación induce a conocer la verdad sobre Dios y a evitar, en general, toda ignorancia, a vivir en sociedad con todo lo que tal cosa lleva consigo, como es, p. ej., respetar a los demás (SANTO TOMAS DE AQUINO, 1947: I-II, q. 94, a. 2).

En primer lugar, podemos subrayar que Santo Tomás no pretende enumerar todos y cada uno de los preceptos, sino más bien delimitar unas zonas de aplicabilidad. Esta cualidad nos permite descubrir una Ley Natural que no es un código estereotipado, un núcleo cerrado e inflexible de preceptos, sino más bien búsqueda continua del bien real y concreto. En segundo lugar, se deduce lógicamente que la naturaleza humana tiene un doble aspecto: una naturaleza genérica en virtud de la cual el hombre tiene unas inclinaciones comunes con las cosas y con los otros animales; y una naturaleza específica propiamente racional, en virtud de la cual busca la verdad sobre Dios y la convivencia social. Por esto,

«la ley natural no es otra cosa que el conocimiento presente naturalmente en el hombre, en virtud del cual él viene dirigido a obrar convenientemente en las acciones propias, sea que le correspondan por la naturaleza genérica, como procrear, comer..., sea por la naturaleza específica, como razonar y cosas similares» (S. THOME AQUINATIS, 1929: In IV Sent., d. 33, q. 1, a. 1).

Al decir esto recordamos que para Santo Tomás las inclinaciones naturales tienen valor moral en la medida en que son reconocidas y ordenadas por la razón, que aprehende los objetos de las 
inclinaciones naturales como bienes humanos. Así, la razón analizando las propias inclinaciones descubre los bienes que debe buscar y deduce los preceptos, es decir, los medios para alcanzar esos fines.

De este modo el "bonum hominis est secundum rationem esse», no significa solamente deducir correctamente los preceptos, sino fundamentalmente vivir en modo tal que las acciones sean adecuadas a las exigencias de la esencia humana y, por tanto, de su perfección. De este modo llamar a la Ley Natural simplemente lex rationis (SANTO TOMAS DE AQUINO, 1947: I-II, q. 94, a. 2, ad. 3) es una consecuencia lógica de la raigambre ontológica del deber ser del hombre.

\subsection{RELACIÓN ENTRE LA LEY NATURAL Y LA LEY HUMANA.}

Hablando sobre la utilidad de la ley, Santo Tomás reconoce que el hombre tiene una cierta disposición para la virtud, pero dice que solamente puede ser conseguida mediante una cierta disciplina. Y esto, especialmente para los individuos «rebeldes y propensos al vicio» con los cuales es necesario usar la fuerza y el miedo, para que no hagan daño a los demás y ellos mismos con la costumbre se vuelvan virtuosos:

«esta disciplina que obliga mediante el temor a la pena, es la disciplina de la ley. Luego era necesario para la paz y la virtud de los hombres que se instituyeran las leyes, porque como dice el Filósofo en I Polit.: si bien el hombre ejercitado en la virtud es el mejor de los animales, cuando se aparta de la ley y la justicia es el peor de todos ellos. Y es que para satisfacer sus concupiscencias y sus iras, el hombre cuenta con el arma de la razón que no poseen los demás animales» (SANTO TOMAS DE AQUINO, 1947: I-II, q. 95, a. 1).

Ahora bien, para Santo Tomás una ley tiene valor de tal en cuanto es justa, su fuerza depende del nivel de justicia, por esto en tanto tiene fuerza de ley en cuanto de justicia; y un hecho humano es justo en la medida en que está de acuerdo con las normas de la razón y de éstas la primera, como hemos dicho, es la ley natural. De aquí que la ley humana tendrá fuerza de tal en la medida en que deriva de la Ley Natural, y «si en algo está en desacuerdo con la ley natural, ya no es ley, sino corrupción de la ley» (SANTO TOMAS DE AQUINO, 1947: I-II, q. 95, a. 2).

La ley humana deriva de la ley natural de dos modos: por conclusión y por determinación. Hay derivación por conclusión de la razón cuando el contenido de la ley se deriva como la conclusión de un juicio o silogismo práctico a partir de principios, al modo de las ciencias; por ejemplo, del principio natural de que no se debe hacer mal a nadie deriva el precepto de "no matarás». La determinación, en cambio, es una opción (por lo tanto entraña una elección) entre las distintas posibilidades que se le abren al hombre de cumplir los preceptos de Ley Natural; así, por ejemplo, del principio natural «el que peca debe ser castigado", la ley humana establece qué tipo de pena se debe aplicar (SANTO TOMAS DE AQUINO, 1947: Ibid).

Santo Tomás resalta cómo las leyes que resultan del segundo procedimiento reciben toda su fuerza de la ley humana (son por lo tanto derogables y variables); en cambio las que resultan del primer

ORIGEN Y DESARROLL DELIUSNATURALISMO ENTOMAS DE AQUINO 
procedimiento tienen su fuerza a la vez de la Ley Natural y de la ley humana, por consiguiente sólo pueden cambiar o variar en lo que de componente humano tengan, no en cambio, en lo que tienen de natural. De otro lado, siendo la Ley Natural participación de la Ley Eterna en la criatura racional, la ley humana tiene su último fundamento en la Ley Eterna.

Santo Tomás explica esta característica recordando que la ley implica un principio o razón directiva del actuar hacia el fin, y haciendo uso de un principio general de la metafísica de Aristóteles: como en una serie ordenada de agentes (uno subordinado o dependiente esencialmente en su actividad del otro), la acción de los agentes inferiores y subordinados deriva de aquella de un primer agente no subordinado (de otro modo tendríamos un proceso al infinito y no se explicaría la acción actual de la cual parte), así en una serie ordenada de gobernantes, la regla de los subalternos deriva de la regla de un primer gobernante no gobernado. Esta regla es la ley de Dios, supremo gobernador del universo, de la cual toda otra ley tiene valor (SANTO TOMAS DE AQUINO, 1947: I-II, q. 93, a. 3). Por esto mismo, una ley tiene naturaleza de ley en la medida en que está de acuerdo con la recta razón y de tal modo deriva de la Ley Eterna, pero de otro lado la ley humana no puede adecuarse perfectamente a la Ley Eterna en cuanto es más limitada porque no regula sino aquello que le compete, y no todas las cosas que regula la Ley Eterna (SANTO TOMAS DE AQUINO, 1947: I-II, q. 93, a. 3, ad. 3). De este modo resulta evidente que la Ley Natural, en sus primeros principios y en sus conclusiones inmediatas, permanece inmutable porque es una participatio de la Ley Eterna en el hombre y refleja la inmutabilidad y perfección de Dios, la luz de sus primeros principios es evidente. Mientras que la ley humana debido a la imperfección de la razón es mutable, y por otro lado debe adecuarse a las circunstancias específicas de los hombres.

\subsection{CARACTERÍSTICAS DE LA LEY NATURAL.}

Con todo lo dicho hasta el momento se han delineado tácitamente algunas características de la Ley Natural que Santo Tomás explícita y consagra: unidad, universalidad e inmutabilidad.

\subsubsection{Unidad de la ley natural}

Según hemos comentado, los preceptos de la Ley Natural son múltiples porque siguen las inclinaciones naturales. De esto, podríamos deducir lógicamente que hay más de una Ley Natural. Para responder aclaremos en primer lugar que en este orden de preceptos fundado sobre el orden de las inclinaciones los niveles superiores presuponen los inferiores, de donde, p. ej., la conservación del ser individual es el fundamento y condición necesaria para todos los otros valores. Ya habíamos anotado que dentro de la antropología de Santo Tomás la forma sustancial del hombre es el alma racional, y por esto mismo contiene las inclinaciones de su ser específico, pero asume las funciones de la vida vegetativa y sensitiva, y por tanto las inclinaciones de los dos primeros preceptos de la Ley Natural. Esta inclusión o presuposición como hemos Ilamado, consiste en una verdadera transfiguración del nivel inferior en el nivel superior y no una simple yuxtaposición.

De este modo a todas las inclinaciones humanas quien dirige y regula es el alma racional (Cf. VENDEMIATI, 1995: 125-126), reconociendo en los objetos de estas inclinaciones bienes humanos 
que deben buscarse. De donde podemos responder con Santo Tomás que la Ley Natural es una porque todos los preceptos se fundan en una raíz y en ella se unifican, es decir el primer precepto "Bonum est faciendum et prosequendum, malum vitandum» (SANTO TOMAS DE AQUINO, 1947: I-II, q. 94, a. 2, ad. 2).

Esta verdad fundamental no impide la multiplicidad de los primeros principios, porque la razón natural, a pesar de ser una y restar idéntica a sí misma, ejercita su jurisdicción sobre todas las inclinaciones del hombre, y por tanto, se extiende a diversas materias y se ramifica en distintos preceptos. Por tanto, la multiplicidad de preceptos mantienen la unidad en un principio fundamental.

\subsubsection{Universalidad de la ley natural.}

Santo Tomás no ignora el hecho de la variedad de las costumbres humanas y, por tanto, la posibilidad de que determinados actos sean considerados virtuosos para algunos y viciosos para otros. Esto nos introduce en la siguiente característica, la universalidad, y aquí surge la pregunta: ¿La Ley Natural es siempre una, válida para todos, independientemente de las circunstancias humanas? Ahora bien, este problema tiene dos aspectos, el primero es el contenido de la ley, es decir el hecho de que la Ley Natural en un lugar y tiempo sea válida, mientras en otro lugar y en otro tiempo no lo sea. El segundo aspecto es el conocimiento mismo de la Ley Natural, es decir la posibilidad de que sea conocible por todos los hombres de todos los tiempos.

Santo Tomás distingue entre las proposiciones de la razón especulativa y las proposiciones de la razón práctica. La razón especulativa versa sobre cosas necesarias, invariables en su modo de ser; por ello sus proposiciones expresan la verdad sin excepciones, sin que falle en ningún caso, aquí la verdad del principio pasa sin ningún cambio a las conclusiones, y esto aún en el caso de que sea conocido sólo por algunos más preparados intelectualmente: la verdad de carácter especulativo permanece la misma, p. ej., es una verdad para todos que los tres ángulos del triángulo son iguales a dos ángulos rectos, aunque no todos lo entiendan. La razón práctica en cambio, versa sobre conductas, envueltas en circunstancias que son variables, pues se trata de la vida misma del hombre.

Ciertamente también la razón práctica se mueve dentro de principios comunes necesarios, es decir, el primer principio «bonum est faciendum..." y los principios conclusivos inmediatos de las inclinaciones naturales, pero cuánto más se desciende a la realidad humana y a los casos particulares, más excepciones se pueden encontrar.

En este sentido, podemos imaginarnos la Ley Natural como una especie de pirámide, en el vértice están ubicados los principios universales invariables, cuánto más se desciende en la pirámide a través de conclusiones o aplicaciones más excepciones se encontrarán.

Estas excepciones tienen como origen la mutabilidad o defectibilidad de la naturaleza humana que no siempre es recta y puede fallar:

ORIGEN Y DESARROLIO DEL IUSNATURALISMO EN TOMAS DE AQUINO 


\begin{abstract}
«Pero la naturaleza humana es mudable, $y$, por consiguiente, lo que es natural al hombre puede algunas veces fallar. Por ejemplo, es de igualdad natural que se devuelva el depósito al depositante; $y$, por tanto, si la naturaleza humana fuera siempre recta, esta forma debería observarse en todo caso; mas, como a veces la voluntad del hombre se pervierte, hay ocasiones en que el depósito no debe ser devuelto para que un hombre de voluntad perversa no use mal de él; v. gr., si un demente o un enemigo de la república reclamara las armas depositadas (SANTO TOMAS DE AQUINO, 1947: II-II, q. 57, a. 2, ad 1).
\end{abstract}

En este ejemplo puesto por Santo Tomás, la mutabilidad de la naturaleza humana hace que las circunstancias varíen y que, por tanto, en las nuevas circunstancias no sea aplicable el precepto de devolver al dueño los bienes depositados, porque sería irracional devolver el arma al sujeto peligroso.

Esto nos Ileva al otro aspecto de la cuestión: si la Ley Natural es común a todos, ¿como puede ocurrir que haya fallos en el conocimiento de determinados preceptos?, pues hay quienes yerran en relación a ellos. La causa de este fenómeno es la ya dicha: la razón de cada hombre es infalible respecto a los primeros principios, pero puede errar en el proceso conclusivo. Esta misma idea la encontramos cuando Santo Tomás resuelve la cuestión de si la Ley Natural se puede borrar del corazón del hombre. Dice que nada puede borrar del corazón humano los principios universales de la Ley Natural, pero en algunos casos concretos puede suceder que la razón se vea impedida a aplicar los principios a un caso particular, a causa de la concupiscencia y de las pasiones en general.

Podemos resumir diciendo que la Ley Natural en cuanto a los primeros principios comunes (tanto de la razón especulativa como práctica), es la misma en todos los hombres, tanto por la rectitud de su inteligencia, como por el conocimiento que de ellos se tiene. En cuanto a los principios particulares, o principios segundos, que son a modo de conclusiones derivados de los principios comunes, es la misma en la generalidad de los casos; pero en casos particulares pueden existir excepciones en cuanto a la bondad o al conocimiento, bien por fallo en el razonamiento, bien por ignorancia a causa de la perversión de la razón debido a las pasiones o a los malos hábitos. La posibilidad de excepciones se refiere a la imposibilidad de una estabilidad absoluta en el campo de las criaturas mutables y contingentes; la inmutabilidad absoluta y plena es reservada sólo a Dios, mientras la naturaleza humana tiene una mutabilidad esencial, pero no absoluta. Es decir, la naturaleza humana no puede cambiar en sus aspectos esenciales, no sería pensable, por ejemplo, un hombre sin lenguaje, cuerpo, razón, voluntad, o sin el orden ontológico al fin o bien último; pero si pueden, por ejemplo, las formulaciones derivadas del proceso deductivo de la razón.

Por esto, dice el mismo Santo Tomás, no nos debemos admirar si una acción es considerada viciosa en un tiempo y lugar mientras en otro tiempo y lugar no lo es; de esto, sin embargo, no se debe deducir que no hay nada naturalmente justo y honesto (S. THOME AQUINATIS, 1931: I, lect. 3, n. 33), sino que la materia es tan amplia que a veces no se tiene certeza perfecta. Por esto, la Ley Natural no es impuesta por Dios como un modelo extraño, sino que se revela en la misma razón cuando ésta indaga sobre la naturaleza y su orden. La doctrina de la Ley Natural en Santo Tomás es esta capacidad de saberse orientar en la búsqueda de aquello que lo realiza como ser humano (Cf. SCOLA, 1982: 197). 


\subsubsection{Inmutabilidad de la ley natural}

Esta característica tiene que ver con la posibilidad de que la Ley Natural cambie de algún modo; si ésta se fundamenta en la misma naturaleza humana, ¿cómo podría cambiar sin tener que hablar de un cambio en la naturaleza del hombre? , si no cambia ¿dónde tiene cabida la libertad del hombre? Santo Tomas responde que una Ley Natural teóricamente podría cambiar o bien por adición o bien por sustracción (SANTO TOMAS DE AQUINO, 1947: I-II, q. 94, a. 5). Es claro que no es posible una mutación por sustracción en cuanto a los primeros principios, porque no puede dejar de ser recto lo que ella prescribe, es decir, no puede dejar de ser Ley Natural algo que antes lo fue. Esto es coherente con el fundamento metafísico que hemos delineado en Santo Tomás: la rectitud del obrar humano se mide por los fines propios de la naturaleza humana, los cuales se manifiestan por las inclinaciones naturales; para que algo dejara de ser Ley Natural (lo recto natural) sería necesario que alguna tendencia humana dejara de existir, lo cual sólo sería posible mediante una mutación de la naturaleza humana que afectase a la esencia del hombre, y esto no es posible. Santo Tomás ve la posibilidad de una mutación por sustracción en casos particulares y excepcionales en cuanto a los preceptos secundarios o conclusiones derivadas de los primeros principios, y esto por causas especiales que impiden su observancia (SANTO TOMAS DE AQUINO, 1947: Ibid). Estas causas son las anotadas anteriormente al hablar de la universalidad, es decir, la defectibilidad de la naturaleza humana.

Para el Santo Doctor se puede dar una mutación por adición en el sentido de que se pueden dar disposiciones de ley positiva (humana o divina) que se añaden a la materia regulada por la Ley Natural y que la especifican en las circunstancias, por ejemplo, la ley natural impone de penalizar los pecados pero no indica la forma, esto viene fijado por la ley positiva.

Caso particular de mutación por adición se da en la propiedad privada y la libertad igual para todos. Santo Tomás analiza estos casos a partir de un texto de S. Isidoro de Sevilla, ubicado en la tercera dificultad al a. 5 de la q. 94 en la I-II, en el cual este último afirma que la libertad, es decir el hecho de que los hombres nacen libres y no siervos, y la comunidad de bienes son de derecho natural, pero en la realidad esto ha sido cambiado por las leyes humanas. Luego, sería la conclusión y el problema a resolver, la Ley Natural cambia. Santo Tomás distingue: hay dos modos por los cuales un precepto puede ser de derecho natural ${ }^{4}$; o porque la naturaleza inclina a eso, o porque la natu-

${ }^{4}$ Santo Tomás usa en muchos lugares los términos ley natural y derecho natural como sinónimos (p. ej., In III Sent.,d. 37, q.1, a.3; In IV Sent., d.33, q.1, a.1). En el Tratado «De Iure» (Summa Theol., II-II, q.57, aa.1-3) establece con mayor claridad la diferencia: el «ius» 0 «iustum» natural es una realidad objetiva, constituida por las cosas naturalmente justas «es algo adecuado a otro, conforme a cierto modo de igualdad» (a. 2), en esta noción prescinde de si a partir de ella se establece o no una regla de conducta «se da el nombre de justo a aquello que, realizando la rectitud de la justicia, es el término del acto de ésta, aun sin tener en cuenta cómo la ejecuta el agente» (a.1). Considerando esto, podríamos decir que en la Ley Natural la razón toma el «ius» de las inclinaciones, es decir lo naturalmente recto, y promulga la Ley Natural. E igualmente que la justicia o exactitud moral de las cosas o acciones naturales no es efecto, sino causa y origen de algunos de los primeros principios del entendimiento práctico. Las cosas justas por naturaleza y, de un modo más general, las cosas 
raleza no lo contradice sino que deja a la razón la especificación o aplicación práctica según la conveniencia, por ejemplo, el hombre nace desnudo pero la Ley Natural no impone el nudismo, antes bien la razón exige el vestido. Así la propiedad privada y la servidumbre son producto de la razón al servicio de la vida humana. Esta idea se aclara aún más cuando Santo Tomás habla específicamente de la propiedad privada

«La comunanza de los bienes se atribuye al derecho natural, no en el sentido de que éste disponga que todas las cosas deban ser poseídas en común y nada como propio, sino en el sentido de que la distinción de posesiones no es derecho natural, sino más bien derivada de convención humana. Por consiguiente la propiedad de las posesiones no es contraria al derecho natural, sino que se la sobreañade por conclusión de la razón humana» (SANTO TOMAS DE AQUINO, 1947: II-II, q. 66, a. 3, ad 1).

Así el Derecho Natural ni prohíbe ni prescribe la propiedad privada; pero la razón hace pasar, por la conveniencia para la vida humana, la propiedad privada en precepto. Como se ve en la mutación por adición no hay ningún cambio absoluto, como sería el caso de que una prohibición se convirtiera en precepto o viceversa.

\section{CONCLUSIONES}

Santo Tomás describe la Ley Natural desde un cuadro de referencia metafísico y antropológico, inspirado en la Revelación. Dentro de este cuadro hemos querido resaltar la relación voluntadrazón que enmarca el concepto mismo de Ley Natural, y que marca una diferencia no radical ni fundamental a mi modo de ver sino sólo de enfoque con Francisco Suárez. Resumamos a grandes líneas este cuadro fundamental de nuestro autor.

Santo Tomás sienta como base de su concepción del universo y del hombre la existencia de un Dios creador y gobernador absoluto de las cosas, un Dios único, primer principio del que dependen en su ser y en su obrar cada una de las criaturas, al que están sujetos aún los actos más insignificantes, los acontecimientos más pequeños que acaecen en el mundo y aún las acciones más libres de los seres dotados de razón.

El hombre, como todo cuanto en él existe de bien y de perfección, no es otra cosa que un reflejo y efecto del agente supremo que es $\operatorname{Dios}^{5}$. El hombre imagen de Dios, tiene un orden específico

buenas por naturaleza, no tienen como causa ejemplar las primeras concepciones prácticas que constituyen los preceptos de la ley natural, sino todo lo contrario. Dicho en otros términos: las cosas justas o buenas naturalmente no son tales por adecuarse con los enunciados de la Ley Natural, sino que estos son justos u honestos en tanto en cuanto son la expresión y enunciado de aquellas (Cf. Summa Theol., I, q.21, a.2.).

${ }^{5}$ Santo Tomàs parte de la idea bìblica de que el hombre es un ser creado por Dios a su imagen y semejanza. Cf. Summa Theol., I, q. 35, a. 2; q. 45, a. 7; q. 93; Summa contra Gentiles., IV, c. 26. 
impreso en su ser: el orden de su obrar en cuanto tal hombre es el orden moral, participación finita de la bondad infinita de Dios, en conformidad con el cual el hombre obra como tal y se perfecciona, a la vez que separándose de él obra contra su propio ser y contra la voluntad divina.

Hay, pues, una íntima relación entre el orden moral y el ser del hombre, porque el orden moral es orden del ser humano. Obrar conforme al orden moral es perfeccionarse, quebrantarlo es degradarse. Así, la Ley Natural es intrínseca al hombre: del ser depende el deber ser, la norma radica en la naturaleza. De ahí que el orden impreso en el ser, participación del intelecto ordenador divino, se encuentre en la naturaleza del ser: es un orden natural.

Es necesario inserir aquí el concepto teleológico: todo ser y toda realidad tienen una tendencia o inclinación natural a realizar su esencia, su fin. Por eso, la Ley Natural es, desde la perspectiva humana, la ley del ser que se realiza en la práctica; el hombre es un «ser que actúa con inteligencia, cuya característica es claramente el actuar por un fin» (SAN TOMMASO D'AQUINO, 1981: 15). Desde la perspectiva divina la Ley Natural es la participación de la Ley Eterna, es decir, participación del proyecto de Dios para dirigir todos los movimientos y actos de las criaturas.

Pero esta participación es en el hombre, como decíamos, inteligente y libre; se da, por tanto, mediante la capacidad de descubrir cuál es su verdadero fin y como debe conducirse libremente para alcanzarlo, en cuanto se halla dotado de una tendencia profunda a obrar el bien y evitar el mal una vez discernidos. En este sentido la razón es norma de conducta pero en cuanto está informada por la Ley Eterna. La participación de la Ley Eterna en el hombre es por tanto fundamentalmente racional, por ser la razón la forma del ser humano.

La voluntad humana, por ser un apetito racional que sigue o expresa la inclinación de la forma del hombre, no puede apetecer ningún bien a no ser que sea presentado por la razón. Su objeto es precisamente el bien aprehendido intelectualmente. Pero a su vez la razón juzga el bien y el mal siguiendo las inclinaciones naturales hacia el bien como habíamos dicho, es decir, siguiendo la orientación puesta por Dios en la naturaleza.

\section{BIBLIOGRAFÍA}

BRAVO G.- MALANDRINO C. (1994). Profilo di storia del pensiero político. Roma: Nuova Italia Scientifica. BASTIT M. (1990). Naissance de la loi moderne. Paris: Pressses Universitaires de France.

CARPINTERO BENÍTEZ, F. (1977). Del derecho natural medieval al derecho natural moderno. Salamanca: Ed. Universidad de Salamanca.

DE FINANCE J. (1971). «Realtá e normativitá della natura umana», in Vita e Pensiero 24 (1971), pp. 753-769. (1994). Etica Generale. Bari: Meridionale.

DELOS J. (1950). La societé Internationale. Paris: Dalloz.

ORIGEN Y DESARROLIO DEL IUSNATURALISMO EN TOMAS DE AQUINO 
GRANERIS, G. (1977). Contribución tomista a la filosofía del derecho. Buenos Aires: Ed. Universitaria Buenos Aires.

LACHANCE L. (1933). Le concept de Droit selon Aristote et S. Thomas. Montreal: A. Levesque. (2001). Humanismo político, individuos y estado en Tomás de Aquino. Navarra: EUNSA LUCAS LUCAS R. (1993). L'uomo spirito incarnato. Milano: Paoline. MACIA MANSO, R. (1976). Doctrinas clásicas iusnaturalistas. Madrid: Instituto de estudios jurídicos. MASSINI CORREAS, C. (2006). La ley natural y su interpretación contemporánea. Navarra: EUNSA. MOHOR ABUAUAD, S. (1973). Ley de derecho natural. Santiago: Ed. Jurídica de Chile.

PIZZORNI R. (1985). Il diritto naturale dalle origine a S. Tommaso d'Aquino. Roma: Cittá Nuova. pp. 324-368.

(1961) «La leicitá della resistenza alla legge ingiusta secondo S. Tommaso», in Aquinas 4 (1961), RHONHEIMER, M. (2006). Ley natural y razón práctica una visión tomista de la autonomía moral. Navarra: Ediciones Universidad de Navarra.

SANCHO IZQUIERDO, M. (1980). Compendio de derecho natural. Navarra: EUNSA.

SANTO TOMÁS DE AQUINO. (1952). Suma contra gentiles, (Edición bilingüe con el texto crítico de la Leonina), 2 vol. Madrid: BAC.

Madrid: BAC.

(1947) Suma Teológica, (Edición bilingüe con el texto crítico de la Leonina), 16 vol.

SAN TOMMASO D'AQUINO. (1992) Le Questioni Disputate, La Veritá, (Con testo latino dell'Edizione Leonina), 3 vol. Bologna: Edizioni Studio Domenicano.

San Tommaso D'Aquino (1981). La Política dei principi cristiani. Siena: Edizioni Cantagalli.

S. THOME AQUINATIS (1950). In duodecem libros Metaphysicorum Aristotelis expositio. Taurini: Marietti. (1931). In Decem Libros Ethicorum Aristotelis ad Nicomachum exposition. Taurini: Marietti. (1929) Scriptum super libros Sententiarum, 4 vol. Parisiis: P. Lethielleux Ed. (1954) De ente et essentia, Opuscula Philosophica. Taurini: Marietti..

SCOLA A. (1982). La fondazione teologica della legge naturale nello «Scriptum Super Sententiis» di San Tommaso d'Aquino. Freiburg: Universitätsverlag.

SIMON, YVES R. M. (1968). La tradición de la ley natural reflexiones de un filósofo. Madrid: Razón y fe.

TEIXIDOR L. (1934). «Suárez y Santo Tomás, notas críticas», en Razón y Fe 13 (1934), pp. 108-120.

VAN OVERBEKE P.M. (1957). «La loi naturelle et le droit naturel selon Saint Thomas», en Revue Thomiste 57. VELA R. (1964). Introduzione, La Legge, en «La somma Teologica», vol. XII. Bologna: Studio Dominicano.

VENDEMIATI A. (1995) La legge naturale nella Summa Theologiae di S. Tommaso d'Aquino. Roma: Dehoniane. 